\title{
Designing a virtual patient as an interprofessional enactment: lessons learnt from the process
}

Song-Ee Ahn and Samuel Edelbring

The self-archived postprint version of this journal article is available at Linköping University Institutional Repository (DiVA):

http://urn.kb.se/resolve?urn=urn:nbn:se:liu:diva-173.5.5.5

N.B.: When citing this work, cite the original publication.

Ahn, S., Edelbring, S., (2020), Designing a virtual patient as an interprofessional enactment: lessons learnt from the process, International Journal of Learning Technology, 15(3), 204-218.

https://doi.org/10.1504/IJLT.2020.112106

Original publication available at:

https://doi.org/10.1504/IJLT.2020.112106

Copyright: Inderscience

http://www.inderscience.com/ 


\title{
Designing a virtual patient as an interprofessional enactment: lessons learnt from the process
}

\begin{abstract}
This study is based on observations of the design process of a virtual patient (VP), which aimed to facilitate interprofessional learning. By following the design process of this particular VP, this study aimed to trace how different practices and the knowledge within these practices were enacted as a VP and to understand the design team's difficulties and challenges. Drawing upon actor-network theory (ANT), the study demonstrates how technology and various practices in healthcare and education were enrolled to build the VP and the different translations that took place during the process. We discuss the results by reflecting on the intertwined relationship among the different enactments of a patient in the different professional practices, the enactment of pedagogical intentions and the role of technology in the design process.
\end{abstract}

Key words: virtual patient design, enactment, simulation in healthcare, interprofessional learning, actor-network theory

\section{Introduction}

There is a need for students in various educational programmes in the health care domain to meet and interact with real patients. However, various factors, such as patient safety and reduced patient time in hospital, limit students' exposure to patients. Using virtual patients (VPs) is valuable when addressing this educational dilemma as thiscan aid in developing a range of crucial competencies: clinical reasoning (Berman et al., 2016; Cook and Triola, 2009; Huwendiek et al., 2009; Peddle et al., 2016), core medical knowledge (Berman et al., 2016), diagnostic skills (Peddle et al., 2016) and examination skills. Additionally, VPs are regarded as a tool for developing students' non-technical skills, such as teamwork and decision making, and for supporting students in learning their professional roles (Peddle et al., 2016). Learners are predominantly future physicians, but VPs can also support interprofessional education, during which students from different professional programmes learn with, from and about each other (Berman et al., 2016).

Peddle et al. (2016) identity two commonly used definitions of virtual patients (VPs): first, a "specific computer program that simulates real-life clinical scenarios; learners emulate the roles of healthcare providers to obtain a history, conduct a physical examination, and make diagnostic and therapeutic decisions" (Cook and Triola, 2009, p.304), and second, "an interactive computer simulation[s] of real-life clinical scenarios for the purpose of medical training, education or assessment" (Ellaway et al. (2008, p.170). VP is an umbrella term that describes several modalities, including virtual reality, virtual worlds, text-based low interactive VPs, full-scale manikins and interactive patient scenarios/conversational agents on computer screens to simulate persons in clinical situations. The predominant modality is computer software that presents interactive patient scenarios on a computer screen using multimedia (e.g. by web browsers). The use of VPs is considered an established practice in medical education, even though it is not a predominant teaching method (Berman et al., 2016). 
Approaches to how VPs are structured for the learner to gather data and how the patient case evolves include narratives, problem-solving, linear strings of pearls and branched VPs (Bearman et al., 2001; Huwendiek et al., 2009). Little has been described about how the patient as a person is brought into being and presented to learners in the VP context. Kenny and Beagan (2004) highlighted the importance of how patient scenarios are presented in problem-based learning. They found that paper-based presentations were dominated by objective biomedical descriptions and that the patient as a person was not apparent to learners.

Several factors and principles are stressed as important for students' deeper learning when designing VPs. One is authenticity (Huwendiek et al., 2009; McCarthy et al., 2013), described as "critical to whether a virtual patient can be considered to be part of a situated learning endeavour, indicating that VPs may provide reliable, valid, and applicable representations of live patients" (Ekblad et al., 2013, p.2). Authenticity is believed to allow students to explore various aspects of healthcare, from clinical knowledge and reasoning through to professionalism, local healthcare policy and structures (Bateman et al., 2013). Furthermore, it can provide students with "doctor in charge" experience (McCarthy et al., 2013). In addition, the designer/author of the case needs to consider the simulation's relevance to students' training and its level of difficulty, revealing gaps in students' knowledge, and what kind of feedback students will receive (Huwendiek et al., 2009; McCarthy et al., 2013; Posel et al., 2009). The suggested principles for designing VPs reflect the sites in which the VPs are located, i.e. the healthcare domain (what is simulated) and educational practice (where it is used).

This study followed the design process of a VP aimed at facilitating interprofessional learning in a Swedish university. By describing and tracking the process in detail, this article explores what knowledge the design process requires and how the knowledge and pedagogical intentions are translated into the VP.

\section{Patient enactment}

We approached our research questions by drawing on actor-network theory (ANT) (Latour, 2005; Law, 2004; Mol, 2002). ANT focuses on the assemblage of humans and materiality in practices, arguing that humans and materiality are mutually emergent and intertwined in social practices. It stresses that the social reality of a practice cannot merely be explained in human terms. To understand the social reality, materiality needs to be included as part of the practice that negotiates with and presupposes the human actor's doing. By adding the concept of non-human actors to the materiality, ANT makes it possible to analyse what the materials do with the human actors and the effects of the assemblage in terms of the relationships, knowledge and reality in a practice (e.g. Fenwick and Edwards, 2010; Latour, 2005; Law, 2004).

To understand the realities of practices, ANT uses the concept of enactment, which signals that something is done in a local practice but, as Mol (2002) points out, leaves the actors vague. The focus is on doing and the effects of doing, rather than the actors on whom, for example, the concept of performance focuses (cf. Goffman, 1990). Enactment differs from construction. The construction concept is used to argue that objects have no fixed or given identities but are results and come to be stabilised. Enactment goes beyond the concept of construction, in that the identity of objects is once again not fixed but requires continuing effort and may change. Furthermore, the enactment of objects tells us that they can take 
multiple forms in various practices. ANT also argues that objects, like humans, are framed as part of events and activities and enacted through a web of heterogeneous relationships.

Mol's study (2002) on atherosclerosis is a pedagogical example of understanding enactment. It is especially relevant to this study, considering its object (a disease) and practice (healthcare). The atherosclerosis, which is visible, measurable and knowable, emerges differently in the various hospital departments. In the outpatient clinic, it is enacted by the distance patients can walk without feeling pain, the patient's capacity to articulate the pain that coincides with the physical examination, the clinical interview, pulsation and skin colour. In the vascular laboratory, a condition becomes atherosclerosis when it meets a minimum value for pressure loss (the difference between blood pressure in the arm and the ankle). When the foot is amputated and moved to the pathology department, the atherosclerosis is perceived as an encroachment of the vessel lumens and a thickening of the vessel wall that is visible under the microscope when an artery piece has been cut out of a body. Atherosclerosis is enacted variously through various arrangements of materials in different practices. The different enactments can coincide and jointly enact an object or exist in parallel (a surgeon and a pathologist understand each other, although they treat atherosclerosis differently) or as a clash (for example, if the pressure loss does not show the expected blood pressure reading, while all the examinations in the outpatient clinic suggest it is atherosclerosis). The different enactments are not a result of different perspectives but of different activities, doings and materials. The enactments are the multiplicity of an object (Mol and Law, 2002).

The intertwined relationships of sociomateriality in a practice can be embedded into an object. The notion of the multiplicity of enactments of an object evokes the questions of what is simulated or what a simulator brings to the simulation. Johnson's study (2008) showed that a pelvic simulator designed in the United States of America (USA) was not a universal representation of a female body. It simulated a female body that was examined and experienced in a particular way. When the simulator, which was approved as high fidelity in the USA, was used in Sweden where the female body is examined differently, it was experienced as inauthentic. The different ways of examining the body produce different ways of feeling and experiencing the body, i.e. different bodies. In other words, what the simulator simulates is not the universal body part (there is no such thing) but an enacted body within a particular practice.

Enactment describes the relationship between subject and object in a specific way. While enactments produce an object that is to be known about, they also "produce a subject, something or someone that does the knowing that corresponds to what is to be known" (Law, 2000, p. 349). The knower and the object of knowledge are located in a relationship and intertwined, and they are co-produced and achieved jointly within a practice (Nicolini et al., 2003). Knowledge is something that is not only articulated but also incorporated into daily activities, instruments and procedures.

As shown earlier, the authenticity concept is embedded in the definition of VPs as a selfevident component of simulation. The enactment concept makes the question of authenticity tricky. While the literature regards reality (and therefore the authenticity of a simulation) as something that exists out there as a single form, enactment tells us that there is a multiplicity of an object and that authenticity is something to be achieved. 
Drawing on ANT, we (re)formulated our research aim as to track and understand how the VP is enacted in a digital form. The research questions were: 1) how different practices and knowledge within the practices are embedded into the VP; 2) how the pedagogical intentions are translated into the VP; and 3) what happens when various practices and thus the different patient enactments are enrolled into the VP.

\section{The study}

\subsection{Study background and authors' roles}

The article follows a design team that used Virtual Interactive Case System (VIC) software. A physician, a teacher in nursing education and a researcher in medical pedagogy formed the design team. The design work was part of a project that planed to investigate how interprofessional learning between medical and nursing students could be supported using computerised VPs. It was decided to design a specific VP scenario to do this project.

The idea for the study behind this article, i.e. to follow and understand the design process, was presented to the desigm team members before their first design meeting. The team agreed and allowed the observing researcher to follow the process. The article authors took different roles. One was a member of the design team. The main author was not in the team and remained a non-participant observer. While the design process was ongoing, the author who was also a member of the team focused on developing the VP.

\subsection{Presentation of technology involved}

The Virtual Interactive Case System (VIC), was selected as the software for the VP (Virtual Interactive Case System, online). The VIC system was originally designed with a diagnostic reasoning process for medical students. In the simulation, the students interact with VPs through a web browser. Different actions, e.g. interview questions and lab tests, are accessible through clicking on six categorised tabs, including "patient history" and "lab tests". Each tab can have submenus with actions relating to the selected choice. When students select an action, a corresponding result is displayed, and the action is registered and evaluated for later feedback. The student can freely access all six tabs in any order. After gathering information by performing actions, students select a concluding part from which no more informationgathering actions can be performed. Assessment questions are posed and concluding feedback is presented, based on the specific student actions. This feedback consists of positive or negative credit points alongside text-based feedback in relation to the specific patient case.

Figure 1. The Virtual Interactive Case System (VIC) 


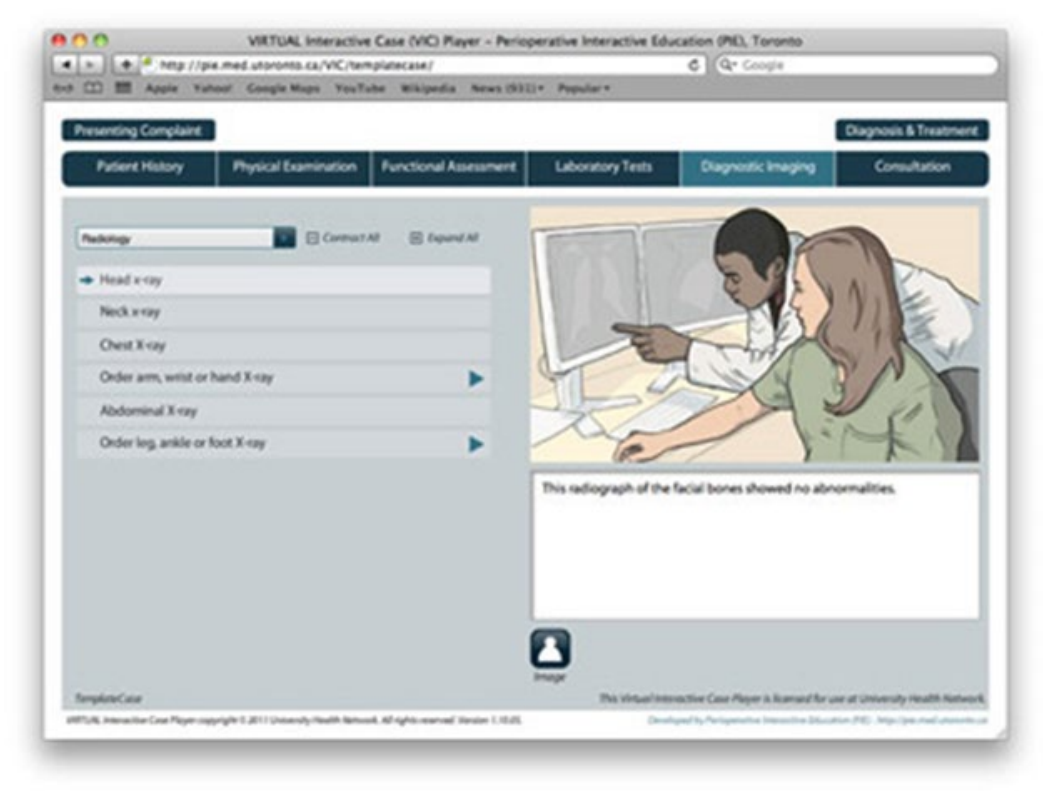

Reproduced from https://pie.med.utoronto.ca/VIC/VIC_content/VIC player.html with permission

In this study, the design team aimed to design a virtual scenario for interprofessional collaboration relevant to nursing and medical students. The team re-designed labels for tabs and actions and added material, such as X-rays, an operation report and photos of the place where the simulation was supposed to happen.

\subsection{Data analysis}

The main data for this study were generated through nine design meetings held during 2017 . Each meeting lasted about 2 hours. All meetings were audio recorded, and some photos were taken. All meeting recordings were transcribed. The materials, such as X-rays and photos of clinics that were used as part of the VP design and working materials such as Excel files and web pages under construction were shared among the design team and the researcher.

Nvivo was used for the analysis of the conversations during the meetings. Nine nodes, such as knowledge in practice and description of the patient, emerged. Under these, different subnodes were developed, such as knowledge in healthcare practice and knowledge in medicine. The analysis showed how the different nodes were each related to other nodes and which nodes emerged most strongly during the different phases of design; for example, the node facilitated/prevented by technology appeared strongly during a later design phase. Some quotes were chosen to illustrate the findings. Some minor adjustments were made during translation from Swedish to English and from spoken to written language to facilitate understanding.

\section{Results}

Figure 2. The different enactments of a virtual patient during the design process 


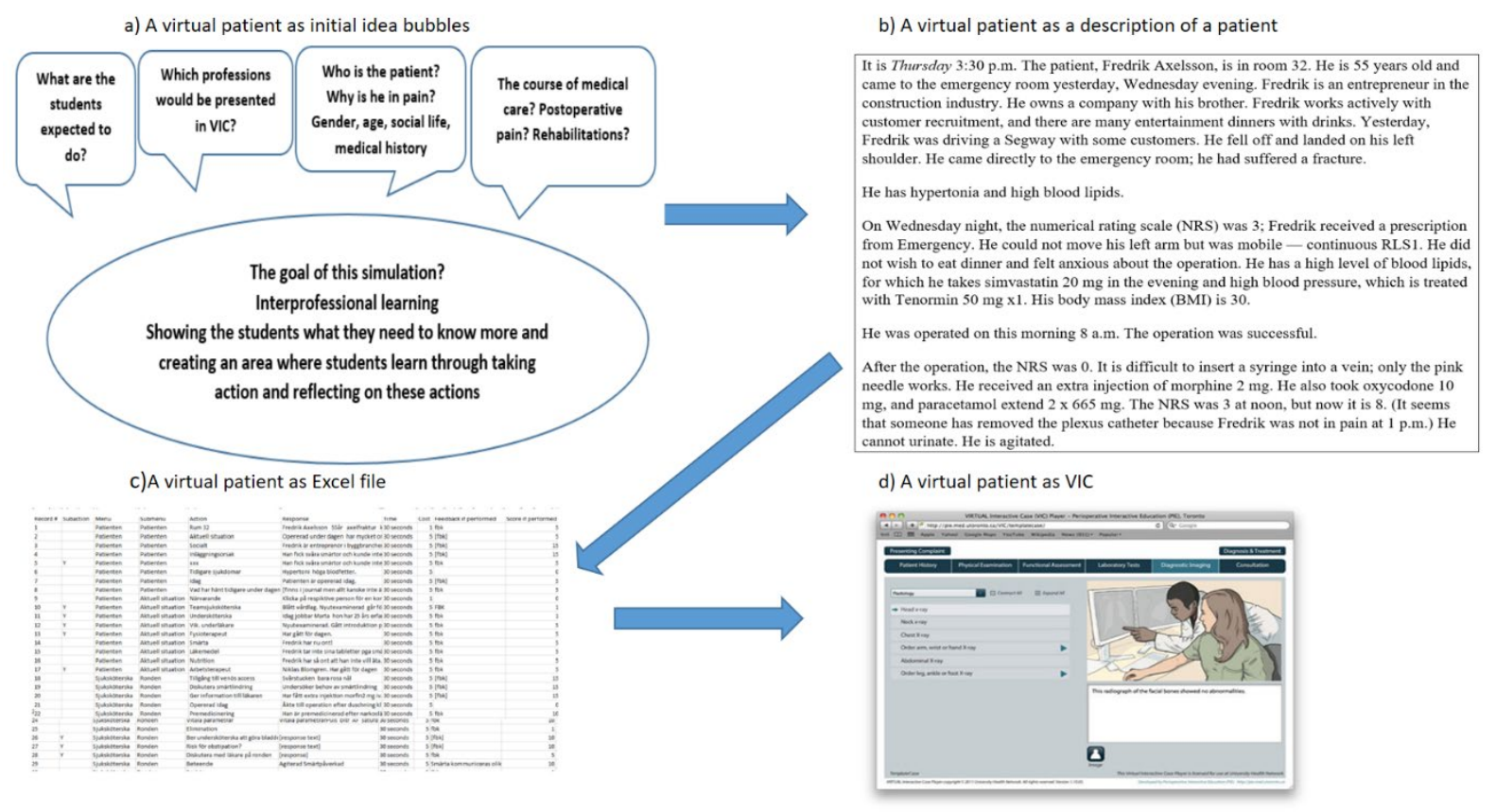

VIC was the virtual patient form that students would encounter, but a VP was enacted and emerged as different forms during the design process. Figure 2 shows different VP forms during the design stages: initial ideas that needed to be decided on are depicted on the left(a), and a coherent description of a patient case is shown on the right(b). This case description was transferred to an Excel file(c) and VIC(d). Excel files can be seen as a structure behind the VIC that students would encounter.

\subsection{Initial idea bubbles}

At the first meeting, the main agenda was to find common ground for the case. The team was aware that the design was aiming to develop students' interprofessional learning and problemsolving ability by using a VP as a pedagogical tool. The first decisions concerned the frame of the VP, how to approach the VP, which professions to include in the case, the patient's medical problem and the simulation's goal. Initially, these questions were discussed in an semi-structured way, but the goal of the project on interprofessional learning functioned as a guide to the decision making. VP development discussions included the following considerations:

But then we [can]think of a shoulder, a damaged shoulder to make it an accessible case. Then we may have a care process in which we interact, [and] we can also have discharge planning. And then we can assume that different teams [of students] come in and do things, and you can make a case where the care process is the focus, and then you form the couple around it. (...) Or we can focus on something specific, as we discussed earlier, about postoperative pain. Partly because I see that here we have a lack of knowledge in many professions. (...) This is another type, but it's rather the question: is the IPL[interprofessional learning] the main focus or is it more (pause)? Do we need to teach how to root out a clinical problem that doesn't have an answer and to discuss it? (...) So what's the overall focus? Both can be run virtually, but if it's 
IPL that's in focus, then I think we'll work on this. This, in my opinion, is a lot easier to do practically. But the question is, what is the aim? (Physician)

Different alternatives for the case scenario were briefly discussed, such as the course of medical care and discharge planning, but the team decided that the case would handle postoperative pain, for various reasons. First, the other scenarios would demand knowledge from professions other than those of the team members. Second, the fact that VIC can only have six tabs was crucial for the decision to eliminate the other scenarios, which involved several professions. Third, pain was regarded as a proper focus of action because there is no single right answer concerning pain treatment, while different professions have to deal with it in everyday practice. The team hoped the case would promote interprofessional discussion to enable a final decision. Additionally, educational needs and pedagogical intentions that slightly differed from fostering interprofessional learning were expressed by team members:

I say there are gaps in knowledge. That's because I see what questions are coming down to us (anaesthesiologists) (...) that's not from a teacher's perspective, but a clinical perspective. You can get very tired of this. Just one example: we've put them [patients] in surgery on pain relief local anaesthesia catheters, and normally it's planned for three to five days of use. When the patient awakens, they're not in pain. Then they [the new doctors] think it's great, and they don't just turn off the pump, but they pull the catheter out too. They don't understand that the patient doesn't have pain because s/he gets [pain relief], it goes well for 2 hours and then at 4 in the morning, the patient is completely in pain! (I say) "But the patient got a catheter." "No, we've taken it away." (Physician)

Based on educational and clinical practice experiences, the physician argued that the scenario and simulation would reveal to students their lack of knowledge in the area. In this way, the physician saw how this pedagogical opportunity could be used to reach a slightly different learning goal, i.e. to understand the treatment of pain and motivate students to learn more about pain.

When the team decided to focus on pain management, the initial VP creation started. The initial patient description can be seen not only as the sum of different fragments presenting aspects of the person's living situation but also as triggers for diagnostic and care actions. Once again, the team worked around some questions, this time concerning the person and the situation: what gender and what age? What happened? Why was the patient in pain? When was this happening? These questions and answers were not yet related to each other, but the fragments were created to facilitate interprofessional learning and meet the additional learning goals that arose during the process. For example, through the description of the patient's background and health problem, the team wished to make students consider different aspects of handling pain. When the team connected the fragments into a coherent story, the VP, 'Fredrik', emerged as a case description.

The first stage of the design process concerned initial ideas and necessary decisions that were made with consideration of what professional knowledge and which practices could be enrolled in the VIC system. The team was aware that the patient was enacted differently in different professions and knew what was possible with the chosen technology and how the learning goals of interprofessional learning and learning about pain could be translated. 


\subsection{Description of the virtual patient Fredrik as a coherent case}

It is Thursday 3:30 p.m. The patient, Fredrik Axelsson, is in room 32. He is 55 years old and came to the emergency room yesterday, Wednesday evening. Fredrik is an entrepreneur in the construction industry. He owns a company with his brother. Fredrik works actively with customer recruitment, and there are many entertainment dinners with drinks. Yesterday, Fredrik was driving a Segway with some customers. He fell off and landed on his left shoulder. He came directly to the emergency room; he had suffered a fracture.

He has hypertonia and high blood lipids.

On Wednesday night, the numerical rating scale (NRS) was 3; Fredrik received a prescription from Emergency. He could not move his left arm but was mobile - continuous RLS1. He did not wish to eat dinner and felt anxious about the operation. He has a high level of blood lipids, for which he takes simvastatin $20 \mathrm{mg}$ in the evening and high blood pressure, which is treated with Tenormin $50 \mathrm{mg} \times 1$. His body mass index (BMI) is 30 .

He was operated on this morning 8 a.m. The operation was successful.

After the operation, the NRS was 0 . It is difficult to insert a syringe into a vein; only the pink needle works. He received an extra injection of morphine $2 \mathrm{mg}$. He also took oxycodone 10 $\mathrm{mg}$, and paracetamol extend $2 \times 665 \mathrm{mg}$. The NRS was 3 at noon, but now it is 8. (It seems that someone has removed the plexus catheter because Fredrik was not in pain at 1 p.m.) $\mathrm{He}$ cannot urinate. He is agitated.

This is about a 55-year-old male patient with a severe shoulder injury. Decision making in the first stage led to a patient description. The different fragments were related and became a comprehensive and coherent case. It may appear to be a simple case, but various types of knowledge about medicine and nursing (e.g. the effects of combinations of various medicines and the relationship between alcohol and pain reduction), healthcare practice (e.g. the logistics) and educational practice (e.g. the teachers' awareness of the lack of knowledge about pain among the students), were enrolled and embedded in the description. Knowledge of medicine and nursing, intertwined with pedagogical intentions, was translated and made the scenario intentionally uncertain. The aim was to create space for medical reasoning and interprofessional collaboration.

Knowledge of mundane activities of healthcare practice and their meaning was a crucial part of the scenario. There was a reason that this case happened on Thursday at 3:30 p.m. For a non-healthcare professional, it may make no difference whether it was Monday or Thursday, but there is a significant difference for those who have insight into how everyday work at a hospital is scheduled and carried out, namely that Fredrik was not handled in the morning rounds. Furthermore, what it meant should be obvious to the students. The students as doctors and nurses in this simulation had rounds activity and needed to prescribe and make a proper weekend medical and care plan. The team reasoned that even though the students who would participate in the simulation had experience of healthcare practices, they had not been active participants but observers. They stressed that ward rounds are part of professional practice that students need to learn how to handle, while also benefiting interprofessional learning. By 
placing the students in a rounds situation, the simulation was intended to work interprofessionally and force the students to make a decision (cf. McCarthy et al., 2013).

This patient scenario was not a real case but was built on fragments commonly observed in healthcare practice. No component of the patient Fredrik was dramatically surprising or puzzling. This was the point of the scenario; the VP was supposed to feel like an authentic case, so that students would feel they had to be able to handle it (cf. Huwendiek et al., 2009; McCarthy et al., 2013). A closer examination of the patient case and why it was built as it was shows that the professional knowledge enrolled for the case was intertwined with the simulation's pedagogical intentions, which were for students to learn about the pain and how to handle it, making them active decision makers, understanding which information on the patient the other professions had access to and learning to communicate interprofessionally.

\subsection{Virtual patient as an Excel file and VIC software: struggling with enactment}

The VP is not a description of a patient. It needs to be translated into tabs and submenus and become a website. The team worked on the construction of the patient via Excel because it is possible to extract an Excel file and export it to VIC (but not vice versa) and the team members had become used to developing VIC in this way. The team often worked in parallel with Excel and VIC to see how their work in Excel appeared in the form of VIC that students would interact with.

Figure 3. A version of Fredrik as an Excel file (extract)

\begin{tabular}{|c|c|c|c|c|c|c|c|c|c|}
\hline 4 & A & B & $\mathrm{c}$ & D & $\mathrm{E}$ & $\mathrm{F}$ & G & $\mathrm{H}$ & \\
\hline 1 & Record\# & Subaction & Menu & Submenu & Action & Response & Time & Cost & Feedback if performed \\
\hline 2 & 1 & & The patient & The patient & Room 32 & Fredrik Axelsson, 55 year old, shoulder fracture, arrived from the emergency yesterday. & 30 seco & & $1 \mathrm{fbk}$ \\
\hline 3 & 2 & & The patient & The patient & Actual situation & Operated during the day, he is in severe pain & 30 seco & & 5 [fbk] \\
\hline $4:$ & 3 & & The patient & The patient & Social & Fredrik is a contractor in the construction industry. Owns the company together with his & s 30 seco & & 5 [fbk] \\
\hline 5 & 4 & & The patient & The patient & The reason for hospitalisation & He suffered severe pain and could not move his shoulder. He went straight to the emerg & g30 seco & & 5 [fbk] \\
\hline 6 & 18 & & Nurse & The round & Venous access & Difficult to give an injection, only pink needle & 30 seco & & 5 [fbk] \\
\hline 7 & 19 & & Nurse & The round & Discuss pain relief & Investigate a need of pain relief & 30 seco & & 5 [fbk] \\
\hline 8 & 20 & & Nurse & The round & Give information to doctor & Has been given extra injection of morphine $2 \mathrm{mg}$ iv. It is not enough, new (dose) needed & 30 seco & & 5 [fbk] \\
\hline 9 & 21 & & Nurse & The round & Operated today & Went to operation after shower $8: 00$ & 30 seco & & 5 \\
\hline 10 & 22 & & Nurse & The round & Premedication & He is premedicated after anesthesiologist contact & 30 seco & & $5 \mathrm{fbk}$ \\
\hline 11 & 41 & & Doctor & The round & Operation report & [operationreport in the medical record] & 30 seco & & 5 [fbk] \\
\hline 12 & 42 & & Doctor & The round & Pain & Discuss och handle the pain & 30 seco & 5 & 5 \\
\hline 13 & 43 & Y & Doctor & The round & Discuss pain relief & Ask NRS scale & 30 seco & & 5 [fbk] \\
\hline 14 & 44 & Y & Doctor & The round & Prescribe pain relief & [response?] & 30 seco & & 5 [fbk] \\
\hline
\end{tabular}

The six tabs (named 'menu' in Excel) representing the interaction structure were given new names: the patient, the nurse, the doctor, the physiotherapist, information from an assistant nurse and medical records. Under the tab "medical records", there were X-rays and an operation report from an actual anonymous case. Submenus (threads) and actions (subthreads) were available under each tab. The students' actions would be scored. After gathering and considering the patient information, the students were expected to select a final section called "conclusion". This was then followed by a feedback section in which students could see all the actions they had selected and get pre-defined feedback on each, along with positive or negative scores.

If VIC were considered as a stage, work with Excel can be understood as behind the scenes. In Excel, where the team did the editorial work, the VP consisted of 20 columns. Only four columns, Menu (tabs), Submenu, Action and Response, became visible to the students in VIC. 
The other columns that concerned scoring the students' actions and giving feedback were worked on within Excel.

Working with VIC involved various translations of patient enactments in healthcare practices and of pedagogical intentions as well as negotiating with technology. The description of a patient as a VP was a result of careful reassembling of professional knowledge and pedagogical intentions. The following section shows the difficulties the team encountered and clashes that enactments aroused while the team transferred the descriptions to enact the VP into the VIC system.

\subsubsection{Caught between enactments of a healthcare patient and pedagogical intentions}

When transferred to Excel and VIC, the patient was fragmented and distributed across the six tabs. Most of the work in this stage concerned the structuring of the threads and subthreads, to find the right place for each piece of information and name them. Under each professional tab were some threads with the same title, but they did not have the same information. This required the team's awareness of which professions had what kind of knowledge about a patient and how a patient was enacted in the professions, so that it would reflect healthcare practice and correspond to the design's goal to support interprofessional learning.

"Even if the same situation arises, then someone with his/her area of knowledge comes to say different things. A nurse will want to give a prescription and a doctor has to give a prescription. And then make a choice" (Physician)

During the simulation the students were expected to find and give information to each other as they would in real healthcare practice. For example, the information on oxycodone was only available under the tab 'nurse'. The work became like writing a detective story. The students needed to find the clues. The main example was the timeline and NRS number.

"I think we have to direct them [the students] a little. So we don't make all the information available. And then I think they [the nurses] say to the doctor that the problem with this patient is that he is in pain. It [pain reduction] doesn't work. The pain was 8 . Or the patient is in pain. And then I think the doctor should start asking, "OK, how bad?" And the next question is: "What has the patient been given until now, what have you given?" (Physician)

"Right. However, do they need a thread labelled "Information to the doctor"? Is it so that they reason and conclude that they actually have to ask these questions?" (Nurse teacher)

"Then the question is, maybe it's the title of the threads that's leading us in the wrong direction, or information is in the wrong thread if it is placed in the Rounds [tab] instead." (Physician)

To enact a VP to support interprofessional learning, the team had to write about the patient's pain in different places and ways so that there would be a meaningful conversation between different professions, simulating the rounds situation. Balancing between "giving information to the students" and "giving a hint to the students what to do" was a major concern. Choosing a word from options such as "discuss" and "ask" was keenly discussed, because it would 
direct students' actions. Finding a place for information and naming the information was a result of translation of the knowledge and pedagogical intentions for the simulation.

Sometimes, the team had to struggle between different pedagogical intentions, such as the experience of an authentic situation and understanding the level of difficulty so it could be a meaningful learning moment (cf, Huwendiek et al., 2009; McCarthy et al., 2013; Posel et al., 2009). When the scenario was transferred to Excel and VIC, the text became "telegram style". It was no longer a story but word fragments that were, however, different kinds of fragments compared with idea bubbles, as a result of translation according to professional practices. For example, the professional language of clinical practice, such as "pain reduction according to the general prescription" and "premedication after contact with an anaesthesiologist" was used as text. This required the students to understand the professional knowledge and actions behind these few words, what information they needed for further action and where they should seek such information. The information was sent and received in a condensed form, which was understood to be difficult for the students to interpret. From the educators' perspective, the team considered that it would hinder simulation when the students were not familiar with the practice yet.

But then it's a very condensed way to describe it. That would only be HT in my department and nothing more. Like hypertension. That would be all the info. It is interpretable in our world. Here, it's too early to write so [because the students do not understand the information](Physician).

\subsubsection{Negotiating with technology and its impact on VP enactment}

At this stage, VIC emerged as an actor that the team needed to negotiate with to translate the embedded knowledge and intentions into the patient description. VIC was not an empty or docile tool. VIC embedded diagnostic practice and praxis from a Canadian healthcare domain (cf. Johnson, 2008). When the team wanted to use it for another purpose in a Swedish context, they came up against the stubbornness of VIC and needed to negotiate with it. An example was time and cost.

And in the Canadian variant, a cost was set [for time], and I've said that I don't want to have [use the function] because we don't talk [in that way] [about the] doctor's 2minute cost. We don't work like that. It directs completely wrong. But that is a reality there. So there they want to have a few [minutes] at as low a cost as possible. Then, a student gets great points.(...) Here, I have set that it would take 10 seconds to ask and receive the answer. It costs zero, because we won't use this. (Physician)

The kind of enactment that was possible in VIC impacted authenticity. Keeping a high level of authenticity was important for design throughout the process. As the physician expressed it: "Fredrik is out there". The patient description was believed to be authentic, with a real but unidentifiable X-ray and operation report. However, when the description was translated into Excel and VIC, the team experienced obstacles. There were different reasons; the patient had now to be enacted as it would be in the different practices while it was translated into VIC. The way in which VIC enacted the patient was not always consistent with different professions. In VIC, the patient as "a person" disappeared but emerged as the medical records, which was consistent with the doctors' medical practice but inconsistent with the nurses' 
professional practice. The nurse teacher pointed out that in nursing practice the patient is an active participant in the process of decision making about care.

From the nursing perspective, (...) it will be, ah, it's against what we're trying to achieve in education, but I think that in this situation you can still ignore that part. Because it's not the main purpose (of the project), but that's communication between the professions, not with the patient. (Nurse teacher)

Furthermore, working with the technology, the team struggled to transfer some of their educational intentions into VIC. They depended on VIC's logic and functions. One important ability that the team wished the students to develop was to sort out information. The team wanted to embed unnecessary and irrelevant information into VIC, so that students would develop the ability to evaluate information. It was difficult to input such information when it did not concern the diagnostic process. It was also impossible for the team to hinder a student from visiting other professions' tabs; a student could access all the threads under the other professions, which meant that $\mathrm{s} / \mathrm{he}$ would not need to ask the other professions for information. Additionally, when a thread included subthreads, VIC marked it with a symbol. The team felt that this function was not pedagogical because VIC influenced the students' actions (Look, here is more information) before the students had assessed the information they already had.

\subsection{The design process stopped}

The design process took much longer than the team anticipated. Enacting the patient Fredrik in such a way that he would be enacted in the different practices and making the enactment (VIC) correspond to these practices was difficult and time-consuming. Using VIC, which was developed for diagnostic practice, for interprofessional learning, and the necessary negotiation with it, was also difficult. The physician believed that the team could bypass this difference by using the points system; the points would alert the students to their lack of knowledge. Additionally, the team planned to write descriptive feedback for the students after their final decision. But it did not work satisfactorily. In the end, VIC was stubborn. The fact that VIC was based on Adobe Flash, whose future is questionable due to its vulnerability to security threats, also meant a future risk in using it. All these reasons led to the decision to postpone the designing of the VP and to use an existing program and case for simulation.

\section{Discussion}

This article explored the process of designing VPs. Grounded in ANT and its idea of enactments, the results illustrate how the different knowledge in the healthcare practices and pedagogical intentions were embedded into the case description and how the different patient enactments as well as pedagogical intentions were negotiated with VIC. The results can be related to Mol's study (2002). While Mol described the multiplicity of the object that emerges in healthcare practices, this study shows what happened when different enactments of an object were translated and conducted as a singular form. As this study is a case study, we do not claim that it is a common design process for interprofessional learning. However three main lessons can be learnt from this particular case, concerning assembling, coinciding and clashing with the patient enactment. 
The first lesson concerns the knowledge required to design a VP for interprofessional learning. The results demonstrate that there could be no VP without knowledge of the healthcare various professions and practices, such as rounds, logistics, etc. A VP is a reassemblage of a patient that emerges in various forms through the different practices. For this case, it was designed to facilitate interprofessional learning that required knowledge of the object 'patient' from different professions. There is no VP without knowledge in enrolled practices. When a VP was translated from a description of a person/case into the VIC program, a problem arose. It can be explained by the clash of different patient enactments in the various healthcare professional practices. VIC did not present the VP as a person to any great extent. Different aspects of the patient needed to be in the foreground for the two professions. For the physician, the physiological parameters, such as those represented by an operation report, needed to be at the forefront, whereas other, more holistic, aspects were important for the nurse. The VP did not enact the kind of patient that nurses meet in their practice, the active participant. This caused a particular clash between VIC and nursing practice. Design for interprofessional learning requires not only knowledge of how the patient in different professions is enacted but also what kind of enactments the chosen technology enables.

The second lesson involves the collision between the patient enactment and the pedagogical intentions. This study's pedagogical intentions were intertwined with knowledge of the practices and embedded into the patient description. The pedagogical intentions also needed to be translated as information, statements, names of subthreads and instructions throughout the VIC system. This required a balance between enacting the high level of authenticity of the healthcare practices and an understanding the students' knowledge level and forming the simulation activities. The team intended to let students experience being professionals and make decisions, while they were aware that the students were not yet professionals.

Therefore, the team spent much time discussing the words to use regarding giving information to the students and guiding their actions (cf. Huwendiek et al., 2009; McCarthy et al., 2013). This process concerned enactment of the person who simulates (cf. Law, 2000). While a virtual patient (the known) is enacted, the VP also enacts the persons who simulate (the knowers, [Law, 2000]). When a VP is enacted as in a practice, the knower enacted is a professional who understands the practice. In this case, the knower is located between the professional practice and educational practice, i.e a student who is acting in the professional role.This case study demonstrates that we can understand the difficulty the team encountered while struggling to guide students' actions as if they were professionals. The second lesson is that we need to be aware that the design of simulation for the student requires careful consideration and hard work to navigate students through simulated professional practices.

The design process was a continuous negotiation between the team and the VIC system. How VIC presented a patient was not always consistent with the professional practice or educational intentions, as the results show. Related to the first lesson, it was apparent that the way VIC enacted a patient was more consistent with medical practice. The other significant clash between technology and the team's intentions was located in VIC's logic, which was developed for a specific medical practice, students' medical diagnostic reasoning, in Canada. A technology is neither neutral nor universal. This can be discussed in relation to Johnson (2008): the practice of diagnosing, the binary logic and a different healthcare practice were all embedded into VIC, and when this technology was used for interprofessional learning, the 
enactment of the patient was unsuccessful. This is the third lesson. The technology involved should be understood as a partner that one negotiates with rather than as an empty tool. Understanding its logic and what is (im)possible with the technology is crucial for the design process.

\section{Conclusion}

The results of this study can be discussed concerning authenticity. The issue of authenticity is an important part of simulation training. However, according to ANT, authenticity does not exist as a singular form, but can only be discussed in terms of practices. We need to understand that there are different enactments of a patient in the healthcare domain. Furthermore, we need to recognise that a technology always creates possibility and impossibility to translate the enactments. In this case, when the different enactments of a patient in the practices were translated into a singular form through a chosen technology, the emerged VP was something that was recognisable and understandable but also not faithful to the enrolled practices. This is the challenge of designing a VP for interprofessional learning. Building a VP for interprofessional learning requires not only knowledge of the practices but also an understanding of what kinds of actions and associations are allowed and negotiable with the chosen technology.

\section{References}

Bateman, J., Allen, M., Samani, D., Kidd, J. and Davies, D. (2013) 'Virtual patient design: exploring what works and why. A grounded theory study', Medical Education, Vol. 47 No. 6, pp.595 - 606

Bearman, M., Cesnik, B. and Liddell, M. (2001) 'Random comparison of 'virtual patient'models in the context of teaching clinical communication skills', Medical Education, Vol. 35 No.9, pp. 824 - 832

Berman, N. B., Durning, S. J., Fischer, M. R., Huwendiek, S. and Triola, M. M. (2016) 'The role for virtual patients in the future of medical education', Academic Medicine, Vol. 91 No. 9, pp.1217 - 1222

Cook, D. A. and Triola, M. M. (2009) 'Virtual patients: a critical literature review and proposed next steps', Medical Education, Vol. 43 No. 4, pp.303 - 311.

Ekblad, S., Mollica, R.F., Fors, U. et al (2013) Educational potential of a virtual patient system for caring for traumatized patients in primary care. BMC Medical Eduation, Vol. 13, No. 110. doi:10.1186/1472-6920-13-110 (Accessed 15 December 2018).

Ellaway, R., Poulton, T., Fors, U., McGee, JB. and Albright, S. (2008). 'Building a virtual patient commons', Medical Teacher, Vol. 30 No. 2, pp.170 - 174

Fenwick, T.J. and Edwards, R. (2010) Actor-network Theory in Education. Routledge, London.

Goffman, E. (1990[1959]). The Presentation of Self in Everyday Life. Penguin, London. 
Huwendiek, S., Reichert, F., Bosse, H. M., De Leng, B. A., van Der Vleuten, C. P., Haag, M., ... Tönshoff, B. (2009) 'Design principles for virtual patients: a focus group study among students’, Medical Education, Vol. 43 No.6, pp.580 - 588.

Johnson, E. (2008) 'Simulating medical patients and practices: bodies and the construction of valid medical simulators', Body \& Society, Vol. 14 No. 3, pp.105 - 128

Kenny, N. P. and Beagan, B. L. (2004) 'The patient as text: a challenge for problem-based learning', Medical Education, Vol. 38 No.10, pp.1071 - 1079

Law, J. (2000) 'Comments on Suchman, and Gherardi, and Nicolini: Knowing as displacing', Organisation, Vol. 7 No. 2, pp.349 - 354

Law, J. (2004) AfterMethod: Mess in Social Science Research, Routledge, Milton Park.

Latour, B. (2005) Reassembling the Social: An Introduction to Actor-network Theory, Oxford University Press, Oxford.

McCarthy, D., O’Gorman, C. and Gormley, G. J. (2013) 'Developing virtual patients for medial microbiology education', Trends in Microbiology, Vol. 21 No. 12, pp.613 615

Mol, A. (2002) The Body Multiple: Ontology in Medical Practice, Duke University Press, Durham.

Mol, A. and Law, J. (2002) 'Complexities: an introduction', in Law, J. and Mol, M. (Eds.), Complexities: Social Studies of Knowledge Practices, Duke University Press, Durham, pp. $1-22$

Nicolini, D., Gherardi, S. and Yanow, D. (2003) 'Introduction: toward a practice-based view of knowing and learning in organizations', in Nicolini, D. Gherardi, S. and Yanow, D. (Eds.), Knowing in Organizations: A Practice-based Approach, M. E. Sharpe, New York, pp.3 - 31

Peddle, M., Bearman, M. and Nestel, D. (2016) 'Virtual patient and nontechnical skills in undergraduate health professional education: an integrative review', Clinical Simulation in Nursing, Vol. 12 No. 9, pp.400 - 410

Posel, N., Fleiszer, D. and Shore, B.M. (2009) '12 Tips: Guidelines for authoring virtual patient cases', Medical Teacher, Vol. 31 No.8, pp.701 - 708

Virtual Interactive Case System [online] http://pie.med.utoronto.ca/VIC/index.htm

(Accessed 1 October 2019). 